\title{
AUMENTO DA VIDA ÚTIL DOS FORNOS DE CAL*
}

\author{
Valtemir Coelho Rodrigues ${ }^{1}$ \\ Leonardo Fidéles da Silva² \\ Arnaldo Nascimento ${ }^{3}$ \\ Nelson de Oliveira Abrita ${ }^{4}$
}

\section{Resumo}

Nos últimos anos face a quantidade significativa de reparos gerais, parciais e emergenciais no revestimento refratário dos fornos em um curto período de tempo (média 02 fornos por ano), haviam paradas prolongadas dos fornos de cal para execução destes reparos onde era necessário prever todos os anos um alto valor para compra de cal, revestimento refratário e mão de obra de manutenção refratária. Afim de reduzir estes custos, aumentar a disponibilidade e produtividade dos fornos, foi feito um estudo e análise para detectar os problemas para serem tratados. Chegamos a conclusão que para aumentar a campanha dos fornos era necessário manter um ritmo estável de produção para evitarmos os choques térmicos no revestimento, treinamento da contratada e implantação do novo projeto para realização de limpeza dos canais o que eliminava o impacto de alavancas contra o revestimento, revisar o projeto o que mudaria a geometria e a composição de algumas peças refratárias, aperfeiçoamento dos monitoramentos do revestimento dos fornos para identificação mais rápido das ocorrências de problema de forma a permitir a aplicação de técnicas corretivas de maneira eficiente além de um intenso trabalho junto ao quadro operacional incluindo cursos e melhorias nos procedimentos que impactavam diretamente na operação correta dos fornos, além disso, melhorias significativas de manutenção contribuíram para melhor performance dos fornos de cal. É possível checar os resultados que este projeto proporcionou aumentando em 06 anos no mínimo a campanha dos fornos eliminando os reparos parciais e emergenciais realizando somente reparos gerais além da redução de custos.

Palavras-chave: Reparos gerais; Fornos; Produtividade, Redução de custo.

\section{Abstract}

\section{INCREASE OF LIME KILN'S LIFE}

I In the last years face a significant amount of general repairs, partial and emergency in the refractory lining of the lime kiln in a short period of time (average 02 kilns per year), had prolonged stoppages of the lime kilns to perform these repairs where it was necessary to provide all years a high value for the purchase of lime, refractory lining and refractory maintenance. In order to reduce these costs, increase availability and productivity of the furnaces, was made a study and analysis on the issues to be dealt with. We came to the conclusion that to increase the campaign of the lime kilns was necessary to maintain a stable rate of production to avoid thermal shocks in the coating, contracted the training and deployment of the new project to carry out cleaning of the channels which eliminated the impact levers against coating, review the project, which would change the geometry and the composition of some refractory parts, improvement of monitoring the lining of the furnace to identify quickly the problem instances to allow the implementation of remedial techniques efficiently as well as intensive work with the operating frame including courses and improved procedures which impacted directly on the correct operation of the furnaces, in addition, significant improvements in maintenance contributed to improved performance of lime kilns. You can check the results that this project provided increasing at least 06 years in the campaign of the kilns eliminating partial and emergency repairs performing general repairs only beyond cost reduction.

Keywords: General repairs; Lime kilns; Productivity; Cost reduction.

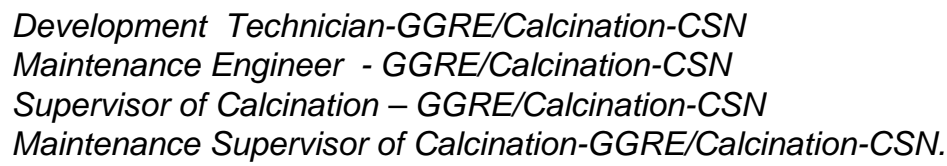




\section{INTRODUÇÃO}

O processo de calcinação é a dissociação dos carbonatos da matéria prima (calcário e dolomita) através da elevação da temperatura e pressão dentro dos fornos. Com a injeção de gás natural e ar ocorre a circulação dos gases resultantes da combustão que arrastam particulados aderindo no revestimento refratário dos Fornos.

Devido ao desgaste que ocorre no revestimento refratário pelo processo de calcinação ocorre queda de tijolos impactando nos parâmetros operacionais, aumentando a pressão interna que a curto prazo pode obstrui o canal impedindo a circulação dos gases causando a sua parada do forno.

Segue abaixo as informações técnicas do forno de cal:

$>$ Identificação: Forno de cal vertical de fluxo paralelo regenerativo de cal Maerz;

$>0$ revestimento refratário do forno corresponde a aproximadamente à 750 toneladas incluindo materiais moldados e não moldados.

\section{MATERIAIS E MÉTODOS}

\section{1 - Objetivos}

Este projeto tem como principal objetivo reduzir o tempo de exposição do executante na limpeza dos canais dos fornos, reduzir o risco de acidentes, aumentar a disponibilidade e produtividade dos fornos.

\section{2 - Metodologia}

A metodologia aplicada foi o PDCA (figura 4), por julgarmos que é a melhor ferramenta para "subir" de patamar, ou seja, para sair do SDCA é necessário "rodar" o PDCA em busca de novas metas. As etapas do PDCA foram seguidas passo à passo.

\subsection{1 - Etapas do PDCA}
a) Identificação do problema;
b) Observação;
c) Análise;
d) Plano de Ação;
e) Execução;
f) Verificação;
g) Padronização e
h) Conclusão.

\section{3 - Desenvolvimento}

\subsection{1 - Problema}

Conforme metodologia, passamos a observar "in loco" o processo e verificamos que ocorreu elevado $\mathrm{n}^{\circ}$ de reparos (Reparos gerais, parciais e emergenciais) no período de 1993 à 2008: 


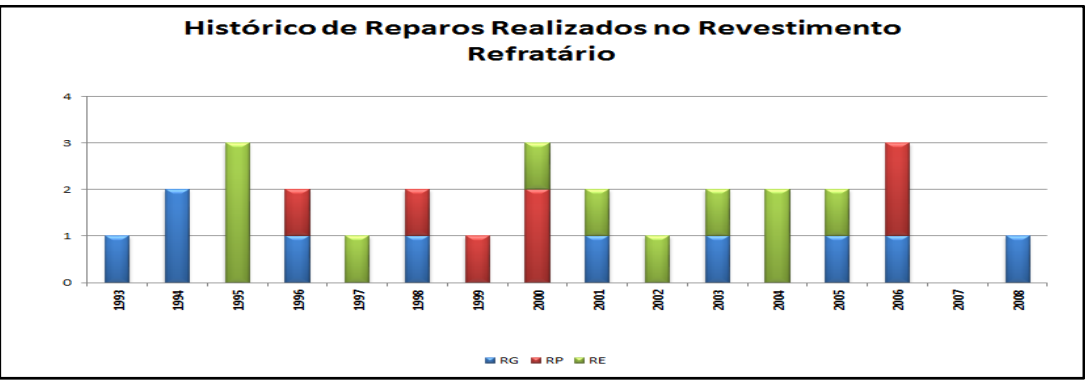

Foi verificado que o desgaste do revestimento ocorria em três setores principais :

$>$ Cubas;

$>$ Arcos;

$>$ Colunas.

\subsection{2 - Causas Fundamentais}

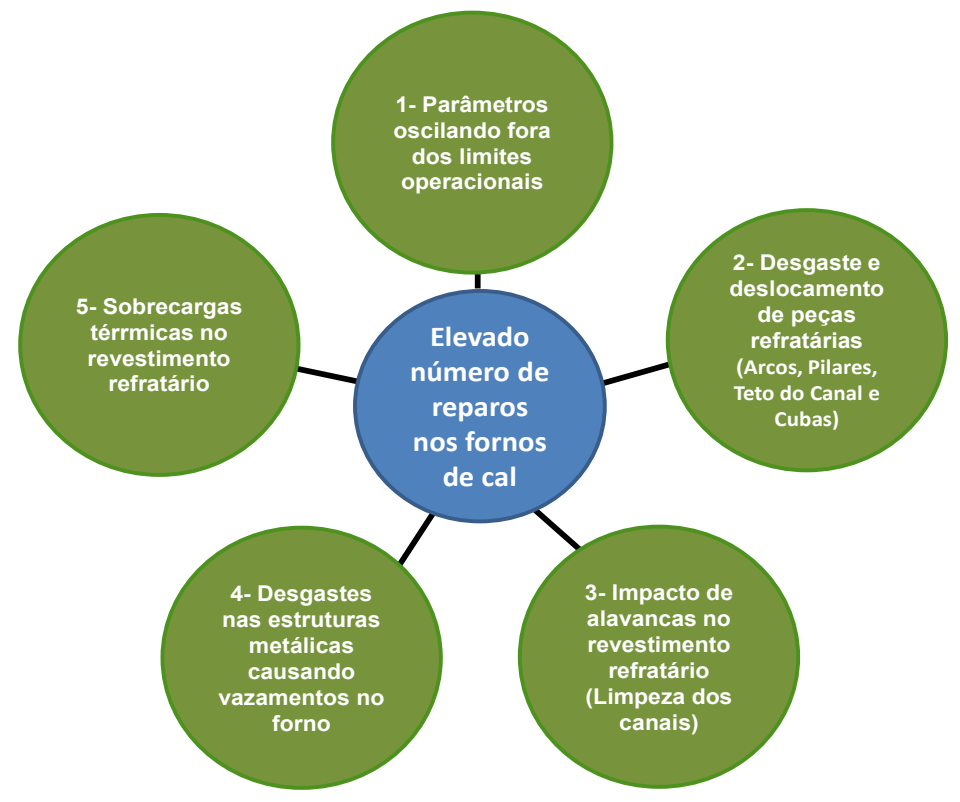

Conforme método de levantamento de problemas, foi verificado que as causas fundamentais do elevado número de reparos é ocasionado pelos seguintes fatores:

1. Parâmetros oscilando fora dos limites operacionais; (Figura 1)

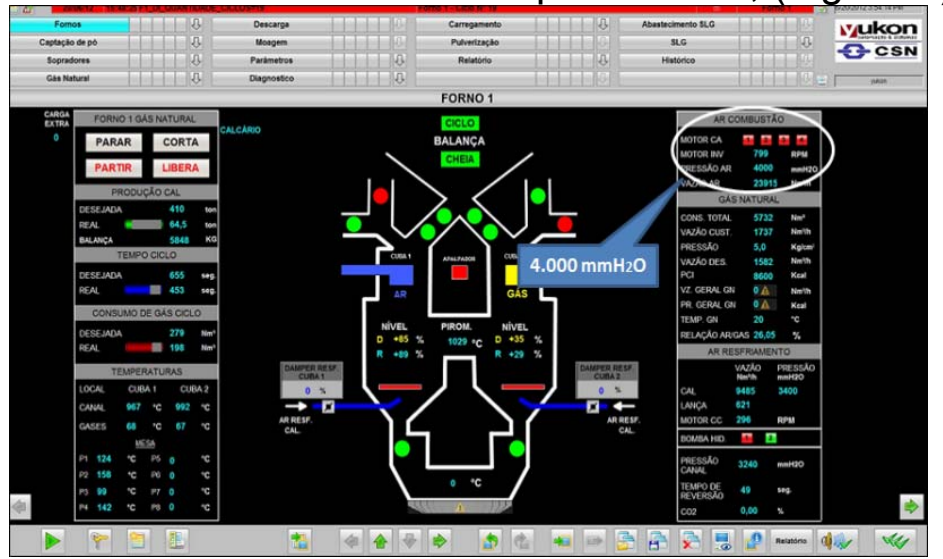

Figura 1. Tela principal do forno 
2. Desgaste e deslocamento de peças refratárias (Arcos, Pilares, Teto do Canal e Cubas); (Figura 2)

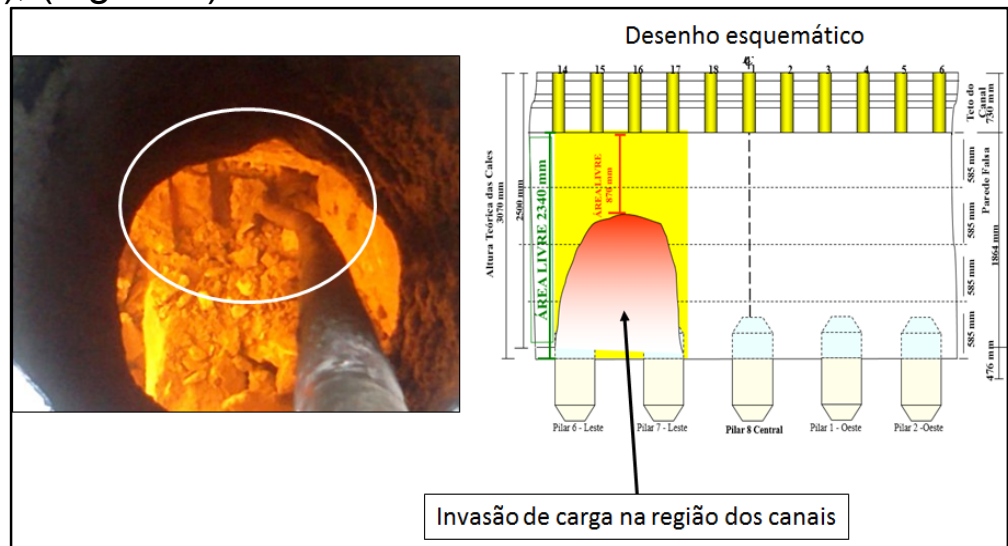

Figura 2. Invasão de carga

3. Impacto de alavancas no revestimento refratário (Limpeza dos canais); (Figura 3)

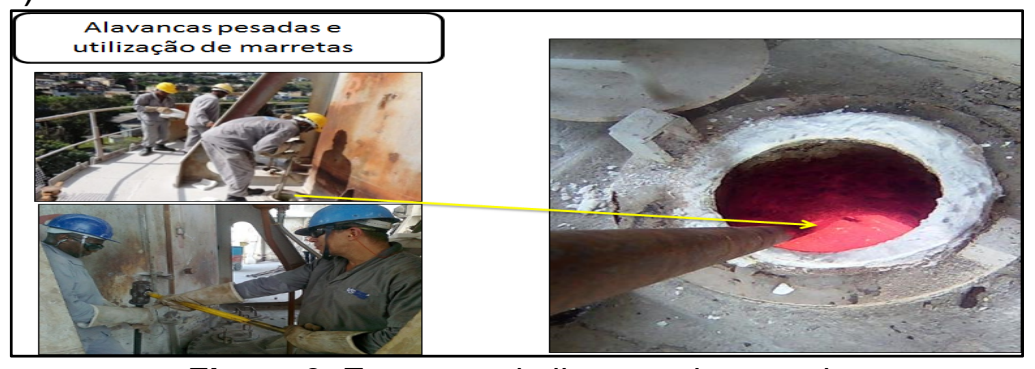

Figura 3. Execução de limpeza dos canais

4. Desgastes nas estruturas metálicas causando vazamentos no forno; (Figura 4)

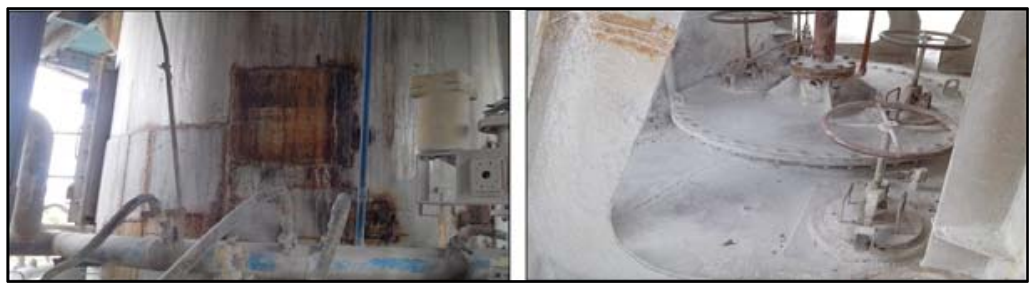

Figura 4. Desgastes de estruturas e estofamento do piso do canal

5. Sobrecargas térrmicas no revestimento refratário;

\section{4 - Implantação}

Foi definido uma proposta de solução: Aumentar a Vida Útil dos Fornos de Cal 
Proposta de solução para aumento da campanha dos fornos de cal:

1- Implantação do novo projeto para realização de limpeza dos canais o que elimina o impacto de alavancas contra o revestimento;

2- Revisão do projeto alterando a geometria e a composição de algumas peças refratárias;

3- Aperfeiçoamento dos monitoramentos do revestimento dos fornos através de preditiva de termografia para identificação mais eficaz de perdas térmicas;

4- Aplicação de técnicas corretivas de maneira eficiente;

5- Treinamento no quadro operacional incluindo cursos e melhorias nos procedimentos que impactam diretamente na operação correta dos fornos;

6- Implantação de novas técnicas que garantam a montagem correta do revestimento refratário;

Foi elaborado um plano de ação e cronograma (figura 5) para desenvolvimento das atividades e implantação do projeto:

\begin{tabular}{|c|c|c|c|c|c|}
\hline O que? & Quem? & Quando? & Onde? & Por que? & Como? \\
\hline $\begin{array}{l}\text { 1- Eliminar } \\
\text { impacto/ choques } \\
\text { no revestimento } \\
\text { refratário }\end{array}$ & $\begin{array}{c}\text { Staff's e } \\
\text { Supervisores }\end{array}$ & $\begin{array}{c}\text { Até } \\
30-12-2013\end{array}$ & $\begin{array}{l}\text { Fábrica de } \\
\text { Cal - CSN }\end{array}$ & $\begin{array}{l}\text { Segurança } \\
\text { Custos } \\
\text { Disponibilidade } \\
\text { Produtividade }\end{array}$ & $\begin{array}{l}\text { Implantando novo projeto } \\
\text { de limpeza de canal } \\
\text { utilizando água } \\
\text { pressurizada }\end{array}$ \\
\hline $\begin{array}{l}\text { 2- Realizar } \\
\text { melhorias no } \\
\text { revestimento } \\
\text { refratário }\end{array}$ & $\begin{array}{c}\text { Staff de } \\
\text { Operação e } \\
\text { Fornecedor } \\
\text { de Refratário }\end{array}$ & $\begin{array}{c}\text { Até } \\
\text { 30-12-2014 }\end{array}$ & $\begin{array}{l}\text { Fábrica de } \\
\text { Cal - CSN }\end{array}$ & $\begin{array}{l}\text { Segurança } \\
\text { Custos } \\
\text { Disponibilidade } \\
\text { Produtividade }\end{array}$ & $\begin{array}{l}\text { Realizando estudos e testes } \\
\text { para desenvolvimento de } \\
\text { peças especiais que } \\
\text { garantam a estabilidade e } \\
\text { conservação do } \\
\text { revestimento }\end{array}$ \\
\hline $\begin{array}{l}\text { 3-Aperfeiçoamento } \\
\text { da técnica de } \\
\text { termografia }\end{array}$ & $\begin{array}{l}\text { Staff de } \\
\text { Operação }\end{array}$ & $\begin{array}{l}\text { À partir de } \\
01-2010\end{array}$ & $\begin{array}{l}\text { Fábrica de } \\
\text { Cal - CSN }\end{array}$ & $\begin{array}{l}\text { Segurança } \\
\text { Custos } \\
\text { Disponibilidade } \\
\text { Produtividade }\end{array}$ & $\begin{array}{l}\text { Aperfeiçoando o } \\
\text { monitoramento do } \\
\text { revestimento dos fornos } \\
\text { para identificação mais } \\
\text { rápido das ocorrências de } \\
\text { problema de forma a } \\
\text { permitir a aplicação de } \\
\text { técnicas corretivas de } \\
\text { maneira eficiente }\end{array}$ \\
\hline $\begin{array}{l}\text { 4- Aplicação de } \\
\text { técnicas corretivas } \\
\text { de maneira } \\
\text { eficiente }\end{array}$ & $\begin{array}{l}\text { Staff de } \\
\text { Operação }\end{array}$ & $\begin{array}{l}\text { À partir de } \\
01-2010\end{array}$ & $\begin{array}{l}\text { Fábrica } \\
\text { de Cal - } \\
\text { CSN }\end{array}$ & $\begin{array}{l}\text { Segurança } \\
\text { Custos } \\
\text { Disponibilidade } \\
\text { Produtividade }\end{array}$ & $\begin{array}{l}\text { Realizando solda cerâmica nas } \\
\text { regiões dos canais }\end{array}$ \\
\hline $\begin{array}{l}\text { 5- Melhoria na } \\
\text { operação do fornos } \\
\text { de cal }\end{array}$ & $\begin{array}{c}\text { Staffe } \\
\text { Supervisor } \\
\text { de } \\
\text { Operação }\end{array}$ & $\begin{array}{l}\text { À partir de } \\
\text { 01-2010 }\end{array}$ & $\begin{array}{l}\text { Fábrica } \\
\text { de Cal - } \\
\text { CSN }\end{array}$ & $\begin{array}{l}\text { Segurança } \\
\text { Custos } \\
\text { Disponibilidade } \\
\text { Produtividade }\end{array}$ & $\begin{array}{l}\text { Realizando cursose } \\
\text { treinamentos relativos ao } \\
\text { processo operacional e } \\
\text { conservação do revestimento } \\
\text { refratário. } \\
\text { Realizar melhorias nos } \\
\text { procedimentos operacionais }\end{array}$ \\
\hline $\begin{array}{l}\text { 6- Garantir a } \\
\text { montagem correta } \\
\text { do revestimento } \\
\text { refratário }\end{array}$ & $\begin{array}{l}\text { Staff de } \\
\text { Operação e } \\
\text { Montadora }\end{array}$ & $\begin{array}{l}\text { À partir de } \\
01-2009\end{array}$ & $\begin{array}{c}\text { Fábrica } \\
\text { de Cal - } \\
\text { CSN }\end{array}$ & $\begin{array}{l}\text { Segurança } \\
\text { Custos } \\
\text { Disponibilidade } \\
\text { Produtividade }\end{array}$ & $\begin{array}{l}\text { Utilizando equipamentos de } \\
\text { última geração e dispositivos } \\
\text { (gabaritos) }\end{array}$ \\
\hline
\end{tabular}

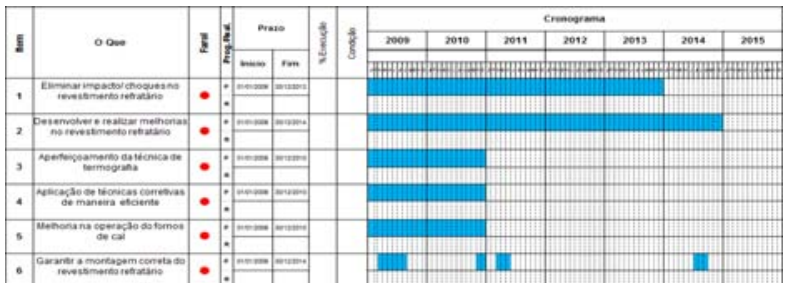

Figura 5. Cronograma de desenvolvimento do projeto 
2.4.1- Eliminar impacto/ choques no revestimento refratário:

> Foi implantado no final do ano de 2013 o novo sistema de limpeza de canal com água pressurizada, o que elimina impactos no revestimento refratário ocasionado pelo uso de alavancas e marretas para. (Figura 6)

Ganhos: Maior confiabilidade e segurança operacional/ Maior disponibilidade e produtividade dos fornos

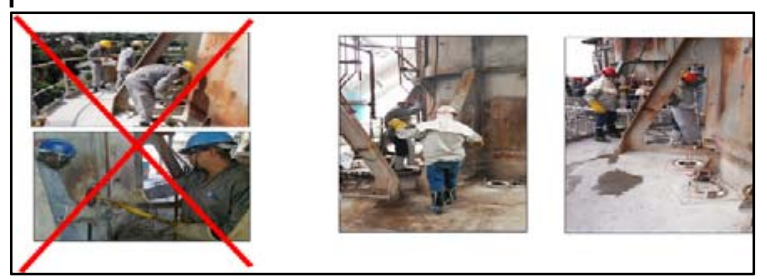

Figura 6. Alteração no procedimento de limpeza de canal

2.4.2- Realizar melhorias no revestimento refratário:

> Para contribuir com o aumento de campanha do refratário foi realizado estudo junto a fornecedora do revestimento que originou no projeto do arco plano que distribui as tensões uniformemente. (Figuras 07e 08)

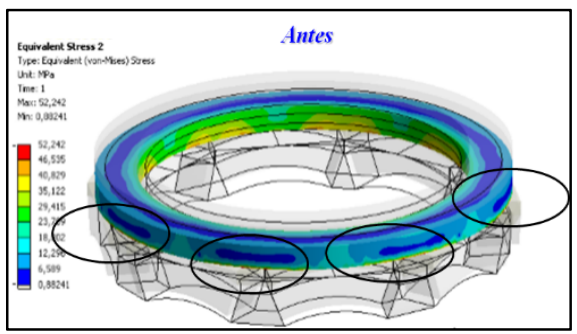

Figura 07. Tensões mal distribuídas

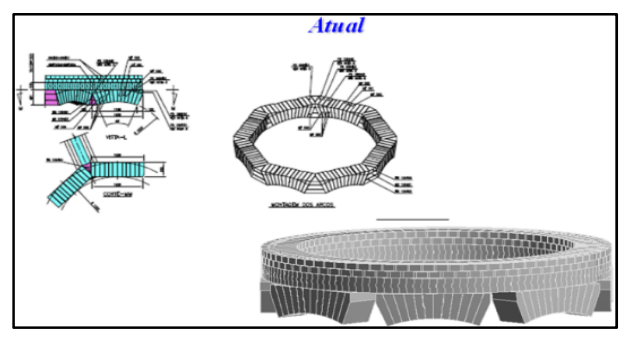

Figura 08. Projeto do arco plano

2.4.3- Aperfeiçoamento da técnica de termografia:

Foi criado planilhas para melhorar o controle e rastreabilidade das anormalidades. (Figuras 09, 10 e 11)

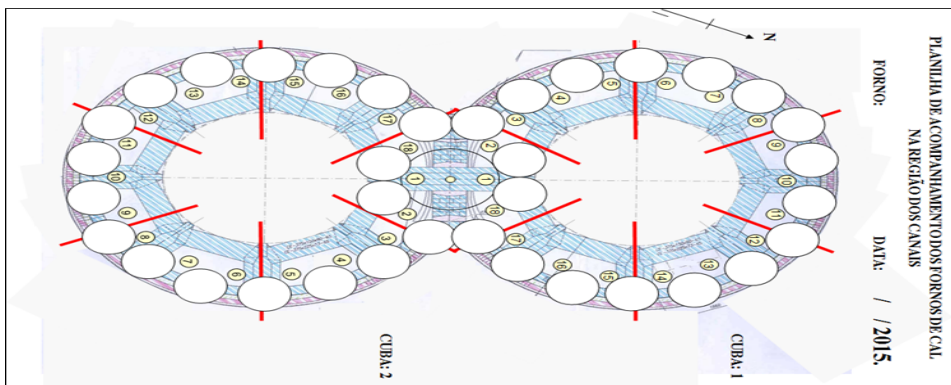

Figura 09. Planilha para verificação de temperatura do piso do canal

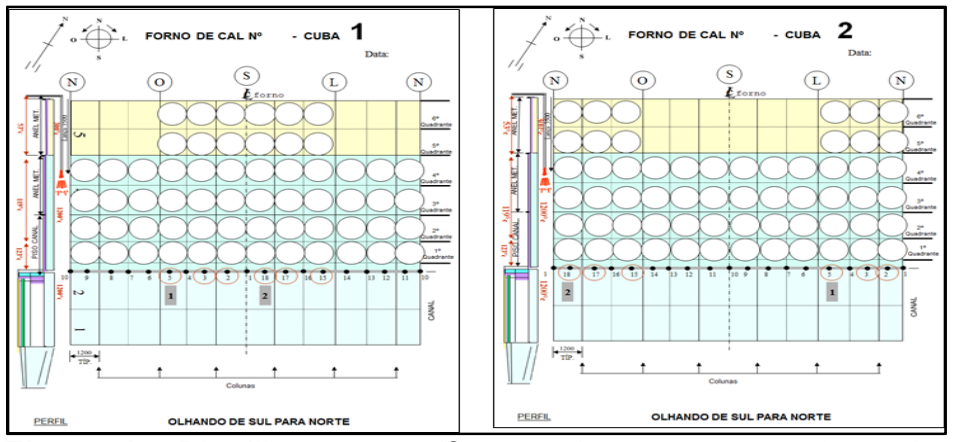

Figura 10. Planilha para verificação de temperatura das cubas 


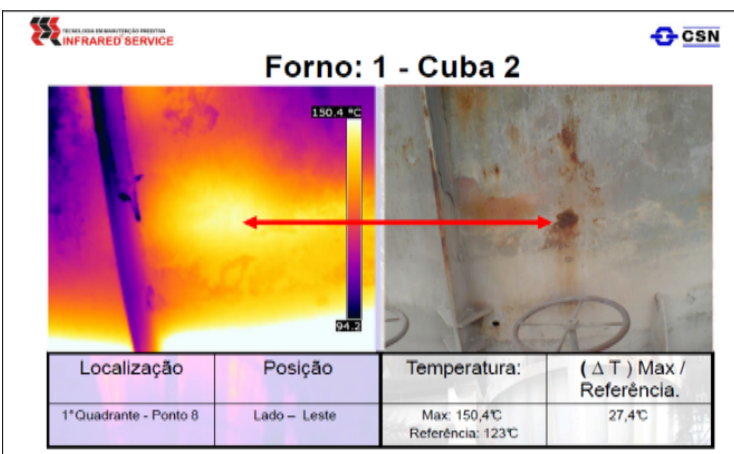

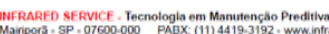

Figura 11. Acompanhamento e identificação do ponto correto com referência de temperatura limite

2.4.3- Aplicação de técnicas corretivas de maneira eficiente:

> Foi desenvolvido técnicas para reparação e reconstrução no revestimento da região dos canais combinando duas técnicas. (Figuras 12, 13, 14 e 15)

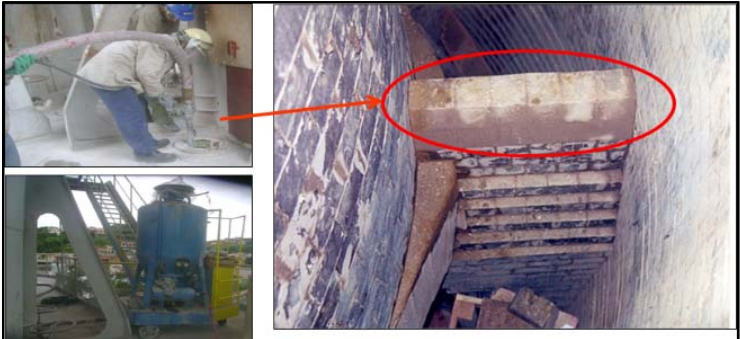

Figura 12. Projeção de massa Recomposição do pilar

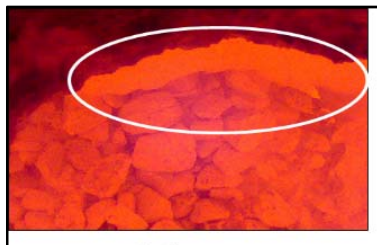

Antes

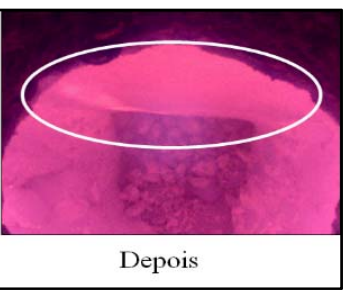

Figura 14. Verificação In Loco do Antes e Depois da aplicação da solda cerâmica

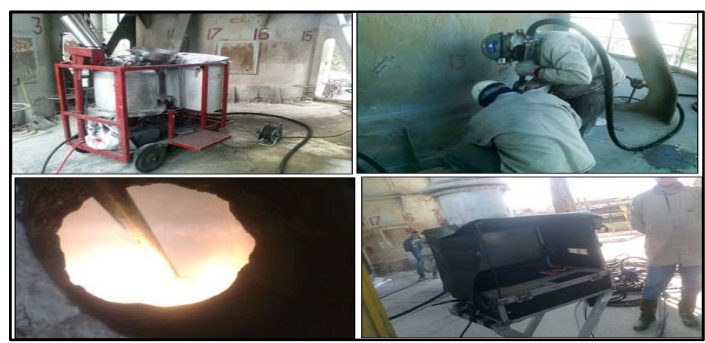

Figura 13. Solda cerâmica e Endoscopia - Reparo nos Arcos e Parede Falsa

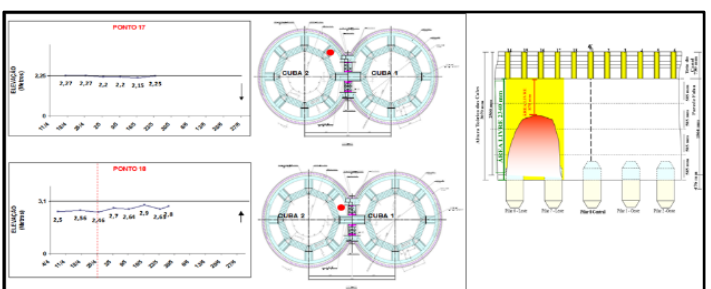

Figura 15. Gráfico de acompanhamento de invasão de carga

2.4.4- Melhorias na operação dos fornos de cal (Procedimentos e Treinamentos):

$>$ Foi aprimorado alguns procedimentos e realizados treinamentos sobre o revestimento refratário.

2.4.5- Garantir a montagem correta do revestimento refratário:

> Para aumentar a campanha do revestimento é necessário também que utilize técnicas específicas para garantir a performance da montagem. (Figuras 16, 17, 18 e 19)

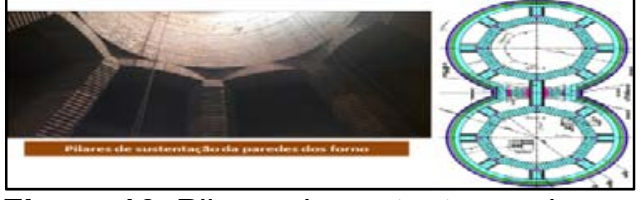

Figura 16. Pilares de sustentação das paredes

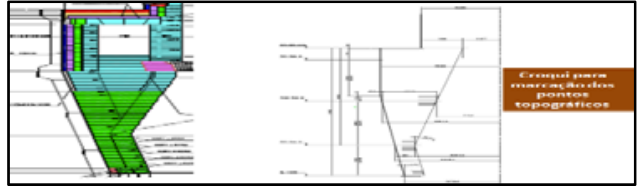

Figura 17. Croqui para marcação das colunas 


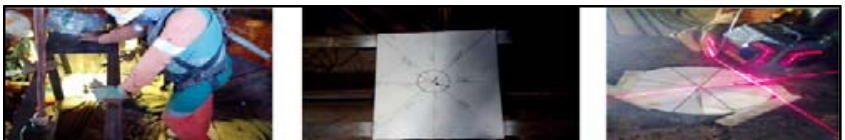

Figura 18. Equipamentos e dispositivos para achar o centro do forno para marcação dos pilares

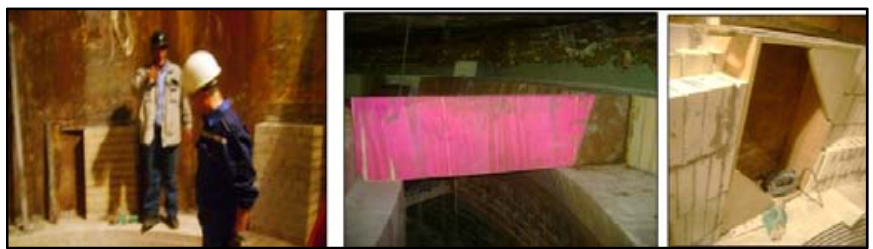

Figura 19. Acompanhamento Full Time de especialistas e utilização de gabaritos para montagem perfeita do revestimento

2.4.6- Ações Implementadas:

> Para reduzir a pressão do forno foi substituído a peneira 03 de dolomita para melhorar o beneficiamento e melhorar a permeabilidade.

Delhoria no sistema de acendimento e aquecimento do Forno de Cal. (Figura 20)

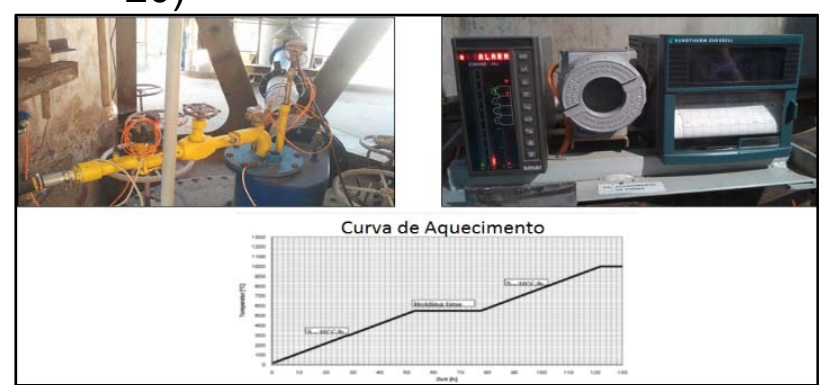

Figura 20. Aperfeiçoamento dos equipamentos para acendimento do forno de cal

\section{RESULTADOS E DISCUSSÃO}

\section{1- O cronograma realizou conforme programado}

3.2- Verificou-se que houve uma queda considerável no número de reparos gerais e eliminação dos reparos parciais.

> Gráfico de acompanhamento: Redução da sequência de reparos

$>$ Aumento da disponibilidade dos fornos de cal.

$>$ Redução da quantidade de reparos e maior tempo para produzir.

> Aumento da disponibilidade dos fornos de cal e atendimento ao novo cliente de cal - Aços Longos:

\section{CONCLUSÃO}

4.1- Aumento de produtividade:

4.2- BenefícioTecnológico e Inovação: Aplicação de novas técnicas e revisão do projeto dos arcos de sustentação das paredes para distribuir as tensões térmicas uniformemente. 


\section{Agradecimentos:}

Rodrigo Luiz Maia Mendes - Coordenador de Calcinação

Técnico de eletrônica e elétrica, técnico de abastecimento, inspetores de manutenção elétrica e mecânica, mecânicos, eletricistas, operadores, líderes de turno e contratadas da Fábrica de Cal pela realização deste projeto. 